\title{
Covid-19 Hastalığında Gelişen Sitokin Salınım Sendromunda CPFA ve Tosilizumab Tedavilerinin Karşılaştırılması
}

\section{Comparison of CPFA and Tocilizumab Treatments in Cytokine Release Syndrome Developing in Covid-19 Disease}

\author{
Tuna ERTÜRK ${ }^{1}(\mathbb{D})$, Bülent Barış GÜVEN ${ }^{1}(\mathbb{D})$, Caner EDiZ $^{2}(\mathbb{D})$, Sevgi KESici ${ }^{1}(\mathbb{D})$, Ayşın ERSOY ${ }^{1}$ \\ ${ }^{1}$ Sağlık Bilimleri Üniversitesi, İstanbul Sultan 2. Abdülhamid Han Eğitim ve Araştırma Hastanesi, Anesteziyoloji ve Reanimasyon \\ Kliniği, İstanbul, TÜRKIYE \\ ${ }^{2}$ Sağlık Bilimleri Üniversitesi, İstanbul Sultan 2. Abdülhamid Han Eğitim ve Araştırma Hastanesi, Üroloji Kliniği, İstanbul, TÜRKiYE
}

Öz.

Amaç: illk olarak Aralık 2019'da Çin'in Wuhan kentinde ortaya çıkan ve Dünya Sağılı Örgütü(DSÖ) tarafından şiddetli akut solunum yolu sendromu koronavirüsü (SARS-CoV-2) olarak adlandırılan yeni koronavirüs, Covid-19 hastalı̆ı̆ıa neden oldu ve küresel ölçekte bir pandemi başlattı. Şiddetli progresyon gösteren Covid-19 olgularında kontrolsüz sitokin üretimi gözlenmekte ve bu durumun artmış mortalitenin nedenlerinden biri olduğu düşünülmektedir.

Covid-19 hastalığı nedeniyle yoğun bakımımızda yatmakta olan ve SARS-CoV-2 virüsünün tetiklediği kontrolsüz sitokin üretimi sonrası sitokin salııım sendromu ve/veya sitokin firtınası geliștiğini düşunndüğümüz hastalara Coupled Plasma Filtration Adsorption (CPFA) ve Tosilizumab tedavileri uyguladık. Çalışmamızda bu tedavilerin etkinliklerini, geriye dönük dosya ve arşiv taraması üzerinden değerlendirmeyi amaçladık.

Materyal ve Metod: Subat-Haziran 2020 tarihleri arasında Covid-19 hastalı̆ı sebebiyle yoğun bakım ünitemizde yatmıs, sitokin salınım sendromu ve/veya sitokin fırtınası geliștiği düşünülmüşs ve tedavi amacıyla CPFA veya Tosilizumab uygulanmış hastalar çalışmamıza dahil edildiler. Her iki tedavi grubundan 20'şer hastanın verileri retrospektif olarak tarandı.

CPFA uygulamaları, her seans 10 saat olacak şekilde ve 12 saat ara verilmek suretiyle 2 seans olarak yapılmıştır. Tosilizumab uygulaması $8 \mathrm{mg} / \mathrm{kg}$ dozdan, maksimum $800 \mathrm{mg}$ olacak şekilde, 1 saatlik sürede intravenöz yoldan yapılıış̧ı.

CPFA ve Tosilizumab uygulamaları başlamadan hemen önce, uygulamalar sonrası 24. saat, 48. saat ve 7. gün ölçülen Sequential Organ Failure Assessment skoru(SOFA), Horowitz indeksi $\left(\mathrm{PaO}_{2} / \mathrm{FiO}_{2}\right)$, ateş, inotrop varlı̆̆l, $\mathrm{SpO}_{2}$ ve ilgili laboratuvar değerleri (IL-6, Lenfosit sayıII, CRP, D-dimer) hasta dosyalarından elde edildi ve karșılaștımalar yapıldı.

Bulgular: CPFA ve Tosilizumab tedavileri sonrası her iki grupta da Horowitz ve SOFA skorları ile SpO2 ve lenfosit değerlerinde artış, ateş, IL-6, CRP ve D dimer değerlerinde ise azalma meydana geldi. SOFA, Horowitz skoru ve $\mathrm{SpO}_{2}$ değerlerindeki artıss, CPFA grubunda anlamlı olarak daha yüksekti. Ek olarak, ates, CRP ve D-dimer değerlerindeki düssme de yine CPFA grubunda anlamlı olarak daha belirgindi. Innotrop desteğinde azalma CPFA grubunda daha belirgin olmasına rağmen istatistiksel açıdan anlamlı bir fark izlenmedi. Sonuç: Covid-19 hastalığında bă̆ışıkıı sisteminin etkilenmesi sonrası gelişen sitokin salııım sendromu ve/veya sitokin firtınası ile hastalık daha ağır seyretmektedir. CPFA ve Tosilizumab tedavileri ile inflamatuar sitokin üretimi kontrol altına alınarak, hastaların oksijenizasyonunda ve klinik bulgularında düzelmeler sağlanmıştır.

Anahtar Kelimeler: Covid-19, Sitokin salınım sendromu, Sitokin fırtınası, CPFA, Tosilizumab

\section{Abstract}

Background: The novel coronavirus, which causes Covid-19 disease and is called severe acute respiratory syndrome coronavirus 2(SARS-CoV-2) by the World Health Organization, was first seen in Wuhan, China in December 2019 and initiated a pandemic on a global scale. Uncontrolled cytokine production is observed in Covid-19 cases with severe progression, and this is thought to be one of the reasons for increased mortality.

We applied Coupled Plasma Filtration Adsorption (CPFA) and Tocilizumab treatments to patients who were hospitalized in our intensive care unit due to Covid-19 disease and who thought that cytokine release syndrome and/or cytokine storm developed after the uncontrolled cytokine production triggered by the SARS-CoV-2 virus. In our study, we aimed to evaluate the effectiveness of these treatments through retrospective file and archive scanning.

Materials and Methods: Patients who had hospitalized in our intensive care unit between February and June 2020 due to Covid-19 disease, were thought to have developed cytokine release syndrome and/or cytokine storm, and were treated with CPFA or Tocilizumab were included in our study. Our study was planned by retrospectively scanning the data of 20 patients from each treatment group.

CPFA treatments were applied for 10 hours each session and 2 sessions with a 12 -hour break. Tocilizumab administration was made intravenously within 1 hour from $8 \mathrm{mg} / \mathrm{kg}$ dose to a maximum of $800 \mathrm{mg}$.

Before CPFA and Tocilizumab treatments and in the 24th, 48th hour and 7th day after CPFA and Tocilizumab treatments, Sequential Organ Failure Assessment scores(SOFA), Horowitz indexes( $\mathrm{PaO} / \mathrm{FiO2}$ ), fever, inotrope requirements, $\mathrm{SpO} 2$ and relevant laboratory values (IL-6, Lymphocyte count, CRP, D-dimer) were obtained from patient files and systemic data.

Results: After CPFA and Tocilizumab treatments, a decrease in fever and IL-6 values, an increase in SpO2 and lymphocyte values, an increase in Horowitz and SOFA scores, and a decrease in CRP and D dimer values were observed. The increase in SpO2 and Horowitz score values was significantly higher in the CPFA group. At the end of the 7th day, a decrease in fever values and an increase in SOFA scores and a decrease in CRP - D dimer values were significantly more pronounced in the CPFA group. A decrease in inotropic support was observed in the CPFA group.

Conclusion: In Covid-19 disease, the disease has a more severe course with cytokine release syndrome and/or cytokine storm that develops after the deterioration of the immune system. Inflammatory cytokine production was controlled with CPFA and Tocilizumab treatments, and improvements were achieved in the oxygenation and clinical findings of the patients.
Sorumlu Yazar/Corresponding Author

\section{Dr. Tuna ERTÜRK}

Sağlık Bilimleri Üniversitesi, İstanbu Sultan 2. Abdülhamid Han Eğitim ve Araştırma Hastanesi Anesteziyoloji ve Reanimasyon Kliniği, Selimiye Mah. Tıbbiye cad. 34668 Üsküdar, İstanbul, TÜRKIYE

E-mail: tunaerturk22@yahoo.com Geliş tarihi / Received: 15.04.2021 Kabul tarihi / Accepted: 07.07.2021

DOI: 10.35440/hutfd.915967

Key words: Covid-19, Cytokine release syndrome, Cytokine storm, CPFA, Tocilizumab 


\section{Giriş}

Aralık 2019'da Çin'in Wuhan kentinde açıklanamayan pnömoni vakaları ortaya çıktı ve Dünya Sağlık Örgütü(DSÖ) tarafından şiddetli akut solunum sendromu koronavirüs 2(SARS-CoV-2) olarak tanımlanan virüsün neden olduğu hastalık Covid-19 hastalığı olarak adlandırıldı. SARS-CoV-2 virüsü, 7 Nisan 2021 itibariyle dünya genelinde 132,4 milyon insana bulaşmış ve yaklaşık 2,8 milyon insanın da ölümüne sebebiyet vermiştir (2).

SARS-CoV-2 virüsünün neden olduğu tablo, hafif-orta hipoksik solunum yetmezliğinden multiorgan yetmezliğine kadar değişen bir hastalık yelpazesine neden olur(3). Covid-19 'un bu şiddetli bulgularının potansiyel bir etiyolojisi, sitokin salınım sendromudur (SSS) ve bunun en şiddetli formu sitokin fırtınası(SF) olarak adlandırılır(4). Bu sendromlar, aşırı inflamatuar sitokin üretimi (IL-6, IL-10 ve tümör nekroz faktörü-a, TNF-a) ile karakterizedir.

Mevcut bilgiler ışığında, şiddetli Covid-19 pnömonisinin patogenezinde rol alan SSS'yi ve şiddetli formu olan SF'yi tedavi etmek için uygulanacak terapötik stratejiler özel dikkat gerektirir(5). SSS veya SF gelişmesi durumunda kullanılan tedaviler; pasif antikor tedavisi olarak da adlandırılan konvalesan plazma kullanımı, anti IL-6 monoklonal antikorlarının kullanımı(Tosilizumab, Siltuximab), interferonların alt tiplerine karşı üretilen antikorların kullanımı(Sifalimumab ), sürekli renal replasman tedavisi (CRRT) ve CPFA gibi yöntemleri içermektedir.

Bu tedavi yöntemlerinden birisi olan CPFA ARDS, sepsis, septik şok, multiorgan yetmezliği gibi endikasyonlarla yoğun bakım hastalarında 2000'li yılların başından itibaren kullanılmaktadır. Bu yöntemin en büyük avantajlarından birisi kandan partiküllü parçaların, sitokinlerin ve mediyatörlerin plazmaferez yöntemiyle uzaklaştırılmasının yanı sıra, beraberinde veya sonrasında hemodiyofiltrasyon uygulanabilmesidir. CPFA'da bulunan plazma filtresi içindeki reçine, yüksek bir yüzey alanına (700 $\mathrm{m}^{21}$ den fazla) sahiptir ve birçok enflamatuar-antienflamatuar medyatör için yüksek bir afiniteye sahiptir. Plazma filtresindeki işlemden geçen plazma hemofiltreye aktarılır. Hemofiltrasyon aşaması, adsorpsiyonla uzaklaştırılmayan küçük moleküllerin ilave arındırılmasına izin verir(7).

IL-6 reseptörü (IL-6R) membrana bağlı interlökin-6 reseptörü (mIL-6R) ve çözünür interlökin-6 reseptörü (sIL-6R) olmak üzere iki forma sahiptir. IL-6, bir kompleks oluşturmak için sIL-6R'ye bağlanır, bu daha sonra sinyal transdüksiyonunu tamamlamak ve proinflamatuar bir rol oynamak için hücre zarı üzerindeki gp130'a bağlanır(8-11). SSS tedavi yöntemlerinden bir diğeri olan Tosilizumab, IL-6 reseptörü monoklonal antikoru olarak sIL-6R ve mIL-6R'ye bağlanabilir ve sinyal transdüksiyonunu inhibe edebilir(11-13). Tosilizumabın şiddetli SSS 'li hastaların tedavisinde etkili olduğunu belirtmek gerekir $(14,15)$.

Çalışmamızın amacı, SARS-CoV-2 virüsünün tetiklediği SSS ve SF sonrası gelişen ARDS, sepsis, septik şok ve multiorgan yetmezliği tablolarındaki hastaların tedavi sürecinde uyguladığımız CPFA veya Tosilizumab tedavilerinin; hemodinami ve sağkalım oranları üzerindeki etkilerini dosya ve arşiv bilgilerinden tarayarak bilgi edinmek ve değerlendirmektir.

\section{Materyal ve Metod}

Sağlık Bilimleri Üniversitesi Hamidiye Klinik Araştırmalar Etik Kurulu onayını takiben (Etik Kurul: 17/06/2020-18521 sayılı yazısı); Anesteziyoloji ve Reanimasyon Kliniği Yoğun Bakım Ünitesi'nde Şubat-Haziran 2020 tarihleri arasında Covid-19 sebebiyle yatan hastalar incelendi. SSS ve SF gelişmesine sekonder olduğu düşünülen ARDS, sepsis, septik şok ve/veya multiorgan yetmezliği gibi tablolar sebebiyle CPFA veya Tosilizumab uygulanmış 20'şer hastanın verileri retrospektif tarandı. Mevcut klinik bulguları doğrultusunda SSS ve SF tablosu düşünülmeyen, 18 yaşından küçük 90 yaşından büyük, işlemin uygulanması için yasal vasilerinden birinin rızası alınmamış, ciddi koagülasyon bozukluğu olan veya antikoagülan kullanımı kontrendike olan ve tedavi edilmemiş kanser ve/veya buna bağlı metastazları bulunan hastalar çalışmadan dışlandılar.

Yoğun bakım ünitemize Covid-19 tanısı ile yatırılan ve SSS ve SF gelişmesine sekonder olduğu düşünülen ARDS, sepsis, septik şok ve/veya multiorgan yetmezliği tabloları bulunan veya sonraki süreçte bu tablolar gelişen hastalardan, mevcut Covid-19 tedavilerine yanıt vermeyen hastalara CPFA veya Tosilizumab uygulama kararı alındı ve deneyimli anestezistler tarafından uygulama yapıldı.

CPFA İşlemi bir polietersülfon plazma filtresi $\left(0,5 \mathrm{~m}^{2}, \mathrm{MPS}\right.$ 05), sentetik reçine kartuşu (alan yüzeyi $700 \mathrm{~m}^{2} / \mathrm{g}$ olan, $140 \mathrm{~g}$ buharla sterilize edilmiş Amberchrom tipi reçine) ve bir polifenilen hemodiyalizör (1.4 m2, HFT 14) ile 180-200 $\mathrm{ml} /$ dk'lık bir kan akışı (Qb) ile 30-40 ml / dk'lık bir plazma akışı (Qp) kullanılan plazma adsorbsiyon cihazı(CPFA, Medtronic Bellco Amplya) ile gerçekleştirildi. İşlem ile beraber ortaya çıkan arteryel hipotansiyon durumunda(<65 $\mathrm{mm} \mathrm{Hg}$ ) hem plazma akışı hem de kan akışı azaltılarak sıvı transfüzyonu ve inotrop infüzyonuna geçildi, inotrop gidiyorsa dozu artırıldı. 11,5-13,5 gauge genişliğinde, çift lümenli femoral santral venöz kateter uygulandı. İhtiyaç durumunda saatlik $40 \mathrm{ml} / \mathrm{kg} / \mathrm{saat}$ olacak şekilde aralıklı hemodiyafiltrasyonu da içerecek şekilde her seansı 10 saat olmak üzere CPFA planlandı. Antikoagülan olarak fraksiyone olmayan heparin veya sitrat uyguladık. Hastaların hemodinamik durumlarına göre 12 saat ara verilmek kaydı ile 2 seans olacak şekilde CPFA uygulamaları yapıldı.

Tosilizumab uygulaması SSS ve/veya SF geliştiği düşünülen, takip edilen hemodinamik ve laboratuvar parametrelerinde kötüye gidiş gözlenen hastalara $8 \mathrm{mg} / \mathrm{kg}$ dozdan, maksimum 800 mg olacak şekilde $100 \mathrm{ml}$ izotonik sodyum klorür $(\% 0,9)$ içinde sulandırılarak 1 saat içinde intravenöz yoldan yapıldı. illk doz uygulaması $600 \mathrm{mg}$ ve altında yapıldığında, klinik ve laboratuvar bulgularındaki değerlerdeki değişimler göz önüne alınarak 12-24 saat içinde 200 mg şeklinde doz tekrarı uygulandı. 
CPFA ve Tosilizumab uygulamaları başlamadan hemen önce, uygulamalar sonrasındaki 24. saat, 48. saat ve 7. gün ölçülen ve/veya hesaplanan SOFA skorları, Horowitz index değerleri $\left(\mathrm{PaO}_{2} / \mathrm{FiO}_{2}\right)$, ateş değerleri, inotrop varlığı, $\mathrm{SpO}_{2}$ ve ilgili birtakım laboratuvar değerleri(IL-6, Lenfosit sayıSı, CRP, D-dimer) dosyalarından ve sistemsel verilerden temin edildi.

\section{istatistiksel Analiz}

Verilerin tanımlayıcı istatistiklerinde ortalama, standart sapma, medyan en düşük, en yüksek, frekans ve oran değerleri kullanılmıştır. Değişkenlerin dağılımı kolmogorov simirnov test ile ölçüldü. Nicel bağımsız normal dağılan verilerin analizinde bağımsız örneklem t test kullanıldı. Nicel bağımsız normal dağılmayan verilerin analizinde bağımsız örneklem Mann-Whitney u test kullanıldı. Bağımlı nicel normal dağılmayan verilerin analizinde Friedman testi kullanıldı. Bağımlı nicel normal dağılan verilerin analizinde tekrarlayan ölçümler varyans analizi kullanıldı. Nitel bağımsız verilerin analizinde ki-kare test, ki-kare test koşulları sağlanmadığında Fischer test kullanıldı. Nitel bağımlı verilerin analizinde Cochrans q test kullanıldı. Analizlerde SPSS 27.0 programı kullanılmıştır.

\section{Bulgular}

CPFA ve Tosilizumab gruplarında hastaların yaşları, cinsiyet dağılımı anlamlı ( $p>0.05$ ) farklılık göstermemiştir. CPFA ve Tosilizumab gruplarında eksitus oranı anlamlı $(p>0.05)$ farklılık göstermemiştir(Tablo 1).

CPFA grubunda tedavi sonrası 24. Saat, 48.saat, 7.gün ateş değeri Tosilizumab grubundan anlamlı $(p<0.05$ ) olarak

Tablo 1. Demografik veriler ve mortalite hızı

\begin{tabular}{|c|c|c|c|c|c|c|c|c|c|c|c|}
\hline & & \multicolumn{4}{|c|}{ CPFA } & \multicolumn{4}{|c|}{ Tosilizumab } & \multirow[b]{2}{*}{$\mathrm{P}$} & \\
\hline & & Mean \pm sd & I & $n-\%$ & Median & Mean \pm sd & / & $\mathrm{n}-\%$ & Median & & \\
\hline \multicolumn{2}{|l|}{ Yaş } & 52,8 & \pm & 10,0 & 51,0 & 58,5 & \pm & 10,4 & 60,0 & 0,228 & ${ }^{t}$ \\
\hline \multirow{2}{*}{ Cinsiyet } & Kadın & 4 & & $20,0 \%$ & & 6 & & $30,0 \%$ & & \multirow{2}{*}{0,606} & \multirow{2}{*}{$x^{2}$} \\
\hline & Erkek & 16 & & $80,0 \%$ & & 14 & & $70,0 \%$ & & & \\
\hline \multicolumn{2}{|l|}{ Ağırlık } & 93,1 & \pm & 13,3 & 92 & 78,5 & \pm & 10,6 & 78,0 & 0,006 & $\mathrm{t}$ \\
\hline \multirow{2}{*}{ Mortalite } & Sağkalım & 14 & & $70 \%$ & & 12 & & $60 \%$ & & \multirow{2}{*}{0,639} & \multirow{2}{*}{$x^{2}$} \\
\hline & Eksitus & 6 & & $30 \%$ & & 8 & & $40 \%$ & & & \\
\hline
\end{tabular}

CPFA grubunda tedavi sonrası 24. Saat, 48.saat, 7.gün SOFA skoru tedavi öncesine göre anlamlı $(p<0.05)$ düşüş göstermiştir. Tosilizumab grubunda tedavi sonrası 24. Saat SOFA skoru tedavi öncesine göre anlamlı ( $p<0.05$ ) düşüş göstermiştir. Tosilizumab grubunda tedavi sonrası 48.saat, 7.gün SOFA skoru tedavi öncesine göre anlamlı ( $p$ $>0.05$ ) değişim göstermemiştir (Tablo 2,3). CPFA grubunda tedavi sonrası 24. Saat, 48.saat, 7.gün lenfosit değeri tedavi öncesine göre anlamlı ( $p>0.05$ ) değişim göstermemiştir.

Tosilizumab grubunda tedavi sonrası 24. Saat, 48.saat lenfosit değeri tedavi öncesine göre anlamlı ( $p>0.05)$ değişim göstermemiştir. Tosilizumab grubunda tedavi sonrası 7.gün lenfosit değeri tedavi öncesine göre anlamlı ( $p$ $<0.05$ ) artış göstermiştir (Tablo 2,3). daha düşüktü.

CPFA grubunda tedavi sonrası 24. Saat, 48.saat, 7.gün ateş değeri tedavi öncesine göre anlamlı $(p<0.05)$ düşüş göstermiştir.

Tosilizumab grubunda tedavi sonrası 24 . Saat ateş değeri tedavi öncesine göre anlamlı ( $p<0.05)$ düşüş göstermiştir. Tosilizumab grubunda tedavi sonrası 48.saat, 7.gün ateş değeri tedavi öncesine göre anlamlı $(p>0.05)$ değişim göstermemiştir (Tablo 2,3).

CPFA grubunda tedavi öncesi $\mathrm{SpO}_{2}$ değerleri Tosilizumab grubundan anlamlı ( $p<0.05$ ) olarak daha düşüktü. CPFA grubunda tedavi sonrası 7.gün $\mathrm{SpO}_{2}$ değerleri Tosilizumab grubundan anlamlı $(p<0.05)$ olarak daha yüksekti. CPFA grubunda tedavi sonrası 24. Saat, 48.saat $\mathrm{SpO}_{2}$ değerleri tedavi öncesine göre anlamlı ( $p>0.05$ ) değişim göstermemiştir. CPFA grubunda tedavi sonrası 7.gün $\mathrm{SpO}_{2}$ değerleri tedavi öncesine göre anlamlı $(p<0.05)$ artış göstermiştir. Tosilizumab grubunda tedavi sonrası 24. Saat, 48.saat, 7.gün $\mathrm{SPO}_{2}$ değerleri tedavi öncesine göre anlamlı ( $\mathrm{p}>$ 0.05 ) değişim göstermemiştir(Tablo 2,3).

CPFA grubunda tedavi öncesi Horovitz skorları Tosilizumab grubundan anlamlı ( $p<0.05$ ) olarak daha düşüktü. CPFA ve Tosilizumab gruplarında tedavi sonrası 24. Saat, 48.saat Horovitz skoru anlamlı ( $p>0.05$ ) farklılık göstermemiştir. CPFA grubunda tedavi sonrası 7.gün Horovitz skoru Tosilizumab grubundan anlamlı ( $\mathrm{p}<0.05$ ) olarak daha yüksekti. CPFA grubunda tedavi sonrası 24. Saat, 48.saat, 7.gün Horovitz skoru tedavi öncesine göre anlamlı ( $p<0.05)$ artış göstermiştir. Tosilizumab grubunda tedavi sonrası 24. Saat , 48.saat, 7.gün Horovitz skoru tedavi öncesine göre anlamlı ( $p>0.05$ ) değişim göstermemiştir(Tablo 2,3).
CPFA grubunda tedavi sonrası 24. Saat, 48.saat, 7.gün IL6 değeri tedavi öncesine göre anlamlı $(p<0.05)$ düşüş göstermiştir. Tosilizumab grubunda tedavi sonrası 24 . Saat , 48.saat, 7.gün IL-6 değeri tedavi öncesine göre anlamlı $(p<0.05)$ düşüş göstermiştir.

CPFA grubunda tedavi öncesi CRP değeri Tosilizumab grubundan anlamlı $(p<0.05)$ olarak daha yüksekti. CPFA ve Tosilizumab gruplarında tedavi sonrası 24. Saat, 48.saat, 7.gün CRP değeri anlamlı ( $p>0.05$ ) farklılık göstermemiştir. CPFA grubunda tedavi sonrası 24. Saat, 48.saat, 7.gün CRP değeri tedavi öncesine göre anlamlı ( $p<0.05$ ) düşüş göstermiştir. Tosilizumab grubunda tedavi sonrası 24 . Saat, 48.saat, 7.gün CRP değeri tedavi öncesine göre anlamlı ( $p>0.05$ ) değişim göstermemiştir(Tablo 2,3). CPFA grubunda tedavi öncesi D-Dimer değeri Tosilizumab 
grubundan anlamlı ( $\mathrm{p} 0.05$ ) olarak daha yüksekti. CPFA grubunda tedavi sonrası 24. Saat, 48.saat, 7.gün D-Dimer değeri tedavi öncesine göre anlamlı $(p<0.05)$ düşüş göstermiştir. Tosilizumab grubunda tedavi sonrası 24. Saat, 48.saat, 7.gün D-Dimer değeri tedavi öncesine göre anlamlı ( $p>0.05$ ) değişim göstermemiştir(Tablo 2,3).
CPFA ve Tosilizumab gruplarında tedavi öncesi, tedavi sonrası 24. Saat, 48.saat, 7.gün İnotrop kullanımı anlamlı ( $p>0.05$ ) farklılık göstermemiştir. Her iki grupta da tedavi sonrası 24. Saat, 48.saat, 7.gün inotrop kullanım oranlarında tedavi öncesine göre anlamlı bir düşüş gözlenmedi ( $p>0.05$ ) (Tablo 2,3).

Tablo 2. Tedavi öncesi değerler

\begin{tabular}{|c|c|c|c|c|c|}
\hline Tedavi öncesi & & Min - Max & Median & \multicolumn{2}{|c|}{ Mean $\pm s d / n-\%$} \\
\hline Ateş & & $36,5-39,6$ & 38,8 & \multicolumn{2}{|c|}{$38,7 \pm 0,8$} \\
\hline $\mathrm{SpO}_{2}$ & & $56,0-98,0$ & 86,5 & \multicolumn{2}{|c|}{$86,1 \pm 8,1$} \\
\hline Horovitz skoru & & $55,0-200,0$ & 87,8 & \multicolumn{2}{|c|}{$94,2 \pm 32,8$} \\
\hline Lenfosit sayısı & & $285,0-1870,0$ & 740,0 & \multicolumn{2}{|c|}{$841,0 \pm 461,5$} \\
\hline IL-6 & & $35,4-324,2$ & 96 & \multicolumn{2}{|c|}{$112,8 \pm 87,8$} \\
\hline CRP & & $12,0-268,0$ & 107,3 & \multicolumn{2}{|c|}{$105,7 \pm 78,7$} \\
\hline D-Dimer & & $343-10200$ & 1085 & \multicolumn{2}{|c|}{$2412 \pm 2970$} \\
\hline SOFA skoru & & $3,0-17,0$ & 9,5 & \multicolumn{2}{|c|}{$9,5 \pm 4,3$} \\
\hline \multirow[t]{2}{*}{ İnotrop kullanımı } & $(-)$ & & & 26 & $65 \%$ \\
\hline & $(+)$ & & & 14 & $35 \%$ \\
\hline
\end{tabular}

\section{Tartışma}

Çalışmamızda, Covid-19 nedeniyle yoğun bakımda takip ettiğimiz, klinik ve laboratuvar bulgularına dayanarak SSS veya daha ağır formu olan SF geliştiğini düşündüğümüz hastalara uyguladığımız CPFA ile Tosilizumab uygulamalarının hemodinamik etkilerini, hastaların dosyalarından ve arşivlerinden geriye dönük olarak araştırdık.

Patojenik insan koronavirüslerinin (HCoV) neden olduğu indüklenmiş hipersitokinemi proinflamatuar ve antiinflamatuar sitokinlerin kontrolsüz aşırı üretimine neden olabilmekte ve bu durum akut akciğer hasarı, ARDS, sepsis, septik şok ve çoklu organ yetmezliği gibi ağır klinik bulguların gelişimine katkıda bulunabilmektedir(16-18). Sitokin fırtınasının en belirgin bulguları yüksek ateş, ilerleyici solunum sıkıntısı, takipne, ferritin artışı, CRP artışı, IL-6 ile diğer inflamatuar sitokinlerin artışıdır. Bununla birlikte Covid-19 enfeksiyonuna bağı I lenfopeni ve D-dimer değerlerinde yükselme de bu bulgulara eşlik etmekte, neticede tüm bunların klinik yansıması olarak desatürasyon, hipotansiyon, düşük Horovitz ve SOFA skorları gelişerek hastada kısır döngüye girmiş bir genel durum bozukluğu oluşturmaktadır(19, 20). Bu şekilde morbidite ve mortaliteyi direk ve olumsuz etkilediğinden dolayı SSS ve SF klinik durumlarının tedavisi önem arz etmektedir(21).

Geliştirilen tedavi protokolleri arasında, SARS-CoV-2 virüsü ve neden olduğu SF için net bir tedavi yöntemi henüz bulunamamıştır. Destekleyici tedaviler, non-invaziv veya invaziv solunum desteği ile konvansiyonel sıvı tedavileri hala Covid-19 hastalığının tedavisinin temelini oluşturmaktadır(22,23). İmmunoterapötik tedavilerden olan anti IL-6 monoklonal antikoru olan Tosilizumab ile kandan partiküllü parçaların, sitokinlerin ve mediyatörlerin plazmaferez yöntemiyle uzaklaştırılmasını sağlayan CPFA tedavisi, kontrolsüz sitokin salınımı ve sonucunda hiperinflamasyona bağlı bozulmakta olan klinik durumlarda kullanılan yöntemlerdendir.
Yapılan bir çalışmada Covid-19 hastalığı sonrası yoğun bakıma kabul edilen hastaların \%98'inde yüksek ateş, \%63'ünde lenfositopeni izlenmiştir. Bu hastalarda ayrıca D-dimer seviyelerinin yoğun bakımda takip edilmeyenlere göre daha yüksek seviyelerde olduğu görülmüştür(1). SARS-CoV-2 enfeksiyonunda izlenen yüksek ateş ile birlikte laboratuvar testlerinden olan yüksek D-dimer seviyeleri ve lenfositopeni hastalığın seyrini de olumsuz yönde etkilemektedir. SARS-CoV-2 enfeksiyonu süresince lenfosit değerlerinde izlenen azalma tanıyı destekleyici bir test olarak da kullanılmıştır. Lenfosit sayısındaki yükselme de klinik iyileşme ile korelasyon göstermiştir(24). Wuhan'da hastanede yatan hastalarla ilgili çoğu çalışma, Covid19'un ortak semptomlarının ateş (\%83-98), yorgunluk (\%70), kuru öksürük (\%59), anoreksi (\%40) miyalji (\%35), dispne (\%31) ve balgam üretimi (\%27) olduğunu ortaya koymaktadır(25-27). Çalışmamızda CPFA ve Tosilizumab uygulamaları sonrası, CPFA uygulamasında daha belirgin olmak üzere vücut sıcaklık değerlerinde anlamlı düşüşler izlendi ve hastaların vücut termoregülasyonunda önemli düzelmeler görüldü. Lenfosit sayıları her iki grupta da artış göstermiştir, ancak klinik iyileşme ile beklenen oranda anlamlı bir artış gerçekleşmemiştir. D-dimer seviyeleri de her iki grupta azalmakla birlikte özellikle CPFA grubunda anlamlı düşüş gerçekleşmiş; hastalığın seyrinin ve kliniğinin düzelmesinde önemli katkı sağlamıştır. Covid-19 hastalı̆̆ı, şiddetiyle orantılı olacak şekilde solunumsal problemlere yol açmakta, vücutta hipoksi, hipoksemi oluşturarak $\mathrm{SpO}_{2}$ değerlerinde düşme ve desatürasyona sebep olmaktadır (28). Horowitz indeksi, kandaki kısmi oksijenin milimetre cıva cinsinden basıncının $\left(\mathrm{PaO}_{2}\right)$ solunan havadaki oksijene $\left(\mathrm{FiO}_{2}\right)$ oranı $\left(\mathrm{PaO}_{2} / \mathrm{FiO}_{2}\right)$ olarak tanımlanır. Horowitz index skoru, yaşa göre değişebilmekle birlikte sağlıklı akciğere sahip insanlarda 350-450 arasında seyretmektedir. 200-300 arası değerler ılımlı akciğer hasarı, 200 altı orta şiddetli akciğer hasarı, 100 altı değerler ise şiddetli akciğer hasarını göstermektedir. 
Tablo 3. Tedavi Öncesi ve Sonrası Klinik ve Laboratuvar Değişimler

\begin{tabular}{|c|c|c|c|c|c|c|c|c|c|c|}
\hline & \multicolumn{4}{|c|}{ CPFA } & \multicolumn{4}{|c|}{ Tosilizumab } & \multirow{2}{*}{$\mathbf{P}$} & \\
\hline & \multicolumn{3}{|c|}{ Mean $\pm s d / n-\%$} & \multirow[t]{2}{*}{ Median } & \multicolumn{3}{|c|}{ Mean $\pm s d / n-\%$} & \multirow[t]{2}{*}{ Median } & & \\
\hline & & & & & & & & & & \\
\hline Tedavi Öncesi & 38,7 & \pm & 0,9 & 38,6 & 38,8 & \pm & 0,6 & 38,9 & 0,822 & $\mathrm{t}$ \\
\hline Tedavi sonrası 24. saat & 37,2 & \pm & $0.8^{*}$ & 37,1 & 38,2 & \pm & $0.6^{*}$ & 38,2 & 0,005 & $\mathrm{t}$ \\
\hline Tedavi sonrası 48. saat & 36,9 & \pm & $0.6^{*}$ & 36,9 & 37,8 & \pm & 0,7 & 37,7 & 0,014 & $\mathrm{t}$ \\
\hline Tedavi sonrası 7. gün & 36,8 & \pm & $0.6^{*}$ & 36,5 & 37,6 & \pm & 0,6 & 37,5 & & $t$ \\
\hline Grup içi değişim p & \multicolumn{4}{|c|}{$0.006^{R}$} & \multicolumn{4}{|c|}{$0.000^{R}$} & 0,042 & \\
\hline \multicolumn{11}{|l|}{$\mathrm{SpO}_{2}$} \\
\hline Tedavi Öncesi & 82,2 & \pm & 9,4 & 84,5 & 90,0 & \pm & 4,1 & 90,0 & 0,003 & $m$ \\
\hline Tedavi sonrası 24 . saat & 86,4 & \pm & 14,1 & 90,5 & 91,3 & \pm & 2,9 & 91,5 & 0,593 & $\mathrm{~m}$ \\
\hline Tedavi sonrası 48. saat & 90,4 & \pm & 9,4 & 93,0 & 91,5 & \pm & 2,4 & 91,5 & 0,266 & $m$ \\
\hline Tedavi sonrası 7. gün & 96,0 & \pm & $2.4^{*}$ & 96,0 & 90,9 & \pm & 4,3 & 92,0 & & $\mathrm{~m}$ \\
\hline Grup içi değişim p & \multicolumn{4}{|c|}{$0.000^{\mathrm{F}}$} & \multicolumn{4}{|c|}{$0.070^{\mathrm{F}}$} & 0,003 & $\mathrm{~m}$ \\
\hline \multicolumn{11}{|l|}{ Horovitz skoru } \\
\hline Tedavi Öncesi & 79,1 & \pm & 21,1 & 81,0 & 109,4 & \pm & 36,3 & 95,8 & 0,019 & $m$ \\
\hline Tedavi sonrası 24. saat & 125,2 & \pm & $82.5^{*}$ & 107,5 & 118,3 & \pm & 28,6 & 104,7 & 0,850 & $\mathrm{~m}$ \\
\hline Tedavi sonrası 48 . saat & 139,6 & \pm & $84.9 *$ & 125,0 & 123,7 & \pm & 33,4 & 117,0 & 0,935 & $\mathrm{~m}$ \\
\hline Tedavi sonrası 7. gün & 187,9 & \pm & $77.9 *$ & 150,0 & 115,5 & \pm & 27,4 & 110,8 & & $\mathrm{~m}$ \\
\hline Grup içi değişim p & \multicolumn{4}{|c|}{$0.001^{F}$} & \multicolumn{4}{|c|}{$0.228^{\mathrm{F}}$} & $0,0<4$ & \\
\hline \multicolumn{11}{|l|}{ Lenfosit sayısı } \\
\hline Tedavi Öncesi & 789,0 & \pm & 553,2 & 525,0 & 893,0 & \pm & 370,9 & 835,0 & 0,325 & $m$ \\
\hline Tedavi sonrası 24 . saat & 1041,0 & \pm & 706,1 & 830,0 & 771,0 & \pm & 285,4 & 790,0 & 0,791 & $\mathrm{~m}$ \\
\hline Tedavi sonrası 48 . saat & 1044,1 & \pm & 581,9 & 920,0 & 799,0 & \pm & 317,0 & 870,0 & 0,327 & $\mathrm{~m}$ \\
\hline Tedavi sonrası 7. gün & 1226,4 & \pm & 807,3 & 1150,0 & 1343,8 & \pm & $643.6^{*}$ & 1125,0 & & $\mathrm{~m}$ \\
\hline Grup içi değişim p & & & $0.100^{\mathrm{F}}$ & & & & $0.008^{\mathrm{F}}$ & & 0,133 & ming \\
\hline IL-6 & & & & & & & & & & \\
\hline Tedavi Öncesi & 140,6 & \pm & 117,4 & 103,0 & 85,1 & \pm & 28,0 & 88,4 & 0,734 & $m$ \\
\hline Tedavi sonrası 24. saat & 78,2 & \pm & $106.6^{*}$ & 18,8 & $22.6^{*}$ & \pm & 13,9 & 18,9 & 0,650 & $\mathrm{~m}$ \\
\hline Tedavi sonrası 48. saat & 46,3 & \pm & $77.4^{*}$ & 9,2 & $22.4^{*}$ & \pm & 24,1 & 12,8 & 0,307 & $\mathrm{~m}$ \\
\hline Tedavi sonrası 7. gün & 14,1 & \pm & $9.7^{*}$ & 7,3 & $41.5^{*}$ & \pm & 64,9 & 21,5 & & $\mathrm{~m}$ \\
\hline Grup içi değişim p & & & $0.001^{F}$ & & & & $0.001^{\mathrm{F}}$ & & 0,079 & $\mathrm{~m}$ \\
\hline CRP & & & & & & & & & & \\
\hline Tedavi Öncesi & 138,7 & \pm & 83,4 & 135,4 & 72,6 & \pm & 60,8 & 59,5 & 0,034 & $m$ \\
\hline Tedavi sonrası 24. saat & 78,6 & \pm & $60.0^{*}$ & 77,8 & 53,2 & \pm & 44,4 & 35,0 & 0,406 & $m$ \\
\hline Tedavi sonrası 48. saat & 65,6 & \pm & $65.4^{*}$ & 40,7 & 43,3 & \pm & 34,0 & 32,7 & 0,653 & $\mathrm{~m}$ \\
\hline Tedavi sonrası 7. gün & 56,0 & \pm & $58.5^{*}$ & 16,0 & 21,7 & \pm & 21,8 & 14,9 & & $\mathrm{~m}$ \\
\hline Grup içi değişim p & & & $0.001^{\mathrm{F}}$ & & & & $0.136^{\mathrm{F}}$ & & 0,379 & $\mathrm{~m}$ \\
\hline D-Dimer & & & & & & & & & & \\
\hline Tedavi Öncesi & 3181,7 & \pm & 2851,8 & 2085,0 & 1642,2 & \pm & 3028,9 & 590,0 & 0,023 & $m$ \\
\hline Tedavi sonrası 24. saat & 1882,0 & \pm & $1302.5^{*}$ & 1945,0 & 1520,4 & \pm & 1955,6 & 912,0 & 0,406 & $\mathrm{~m}$ \\
\hline Tedavi sonrası 48. saat & 1179,4 & \pm & $885.4^{*}$ & 960,0 & 1552,8 & \pm & 1385,1 & 893,0 & 0,568 & $\mathrm{~m}$ \\
\hline Tedavi sonrası 7. gün & 902,1 & \pm & $734.1^{*}$ & 760,0 & 1831,9 & \pm & 1577,7 & 1500,0 & & $\mathrm{~m}$ \\
\hline Grup içi değişim p & & & $0.000^{\mathrm{F}}$ & & & & $0.086^{\mathrm{F}}$ & & 0,172 & $\mathrm{~m}$ \\
\hline SOFA skoru & & & & & & & & & & \\
\hline Tedavi Öncesi & 11,0 & \pm & 3,7 & 10,0 & 7,9 & \pm & 4,4 & 8,0 & 0,149 & $\mathrm{~m}$ \\
\hline Tedavi sonrası 24. saat & 10,1 & \pm & $4.5^{*}$ & 8,0 & 7,0 & \pm & $4.1^{*}$ & 7,5 & 0,210 & $\mathrm{~m}$ \\
\hline Tedavi sonrası 48 . saat & 8,4 & \pm & $4.3^{*}$ & 8,0 & 7,1 & \pm & 4,8 & 8,0 & 0,647 & $\mathrm{~m}$ \\
\hline Tedavi sonrası 7. gün & 6,1 & \pm & $1.2^{*}$ & 7,0 & 7,6 & \pm & 5,3 & 7,5 & & $\mathrm{~m}$ \\
\hline Grup içi değişim p & & & $0.000^{\mathrm{F}}$ & & & & $0.209^{F}$ & & 0,620 & $\mathrm{~m}$ \\
\hline Inotrop kullanımı & & & & & & & & & & \\
\hline Tedavi Öncesi & 6 & & $30,0 \%$ & & 8 & & $40,0 \%$ & & 0,639 & $x^{2}$ \\
\hline Tedavi sonrası 24. saat & 8 & & $40,0 \%$ & & 6 & & $30,0 \%$ & & 0,639 & $x^{2}$ \\
\hline Tedavi sonrası 48. saat & 4 & & $22,2 \%$ & & 6 & & $30,0 \%$ & & 0,701 & $x^{2}$ \\
\hline Tedavi sonrası 7. gün & 0 & & $0,0 \%$ & & 8 & & $40,0 \%$ & & & $x^{2}$ \\
\hline Grup içi değişim p & & & $0.572^{\mathrm{C}}$ & & & & $0.572^{\mathrm{C}}$ & & 0,103 & $x^{2}$ \\
\hline
\end{tabular}

${ }^{\mathrm{t}}$ Independent Samples $\mathrm{t}$ test / ${ }^{m}$ Mann-Whitney u test $/ \mathrm{X}^{2}$ Chi-square test

FFrieadman test Wilcoxon test / Repeated Measures ANOVA / ${ }^{C}$ Cochrans $Q$ test

Horowitz indeksi ARDS teşhisinde önemli rol oynamakta$\operatorname{dır}(29,30)$. ARDS, sepsis ve organ yetmezlikleri gelişmiş, SSS ve SF bulguları olan hastalarımızda düşük $\mathrm{SpO}_{2}$ değerleri ve düşük Horowitz skorları mevcuttu. Her iki grupta da satürasyonlarda artış meydana gelmekle birlikte CPFA uygulaması daha etkin olacak şekilde özellikle 7. günün sonunda oksijenizasyonda anlamlı bir iyileşme sağlamıştır. Her iki grupta Horowitz indeks skorlarında artış meydana gelmiştir, ancak Tosilizumab grubunda bu düzelmeler daha sınırlı izlendi.

Sepsis ve septik şok için iyi bir tanısal belirteç olan ve ön planda altı organ sisteminin değerlendirilmesi sonrası 
çoklu organ işlev bozukluğunun durumunu ve derecesini yansıtan SOFA skorlarında da mevcut laboratuvar ve klinik iyileşmeler sonrası anlamlı düzelmeler izlenmiştir(31). SOFA skorlarındaki düzelmeler CPFA grubunda tedavi sonrası tüm süreçlerde belirgin olacak şekilde izlenmişken, Tosilizumab grubunda tedavi sonrası 48. saat ve 7 . günde sınırlı kalmıştır. Her iki grup SOFA skorları ortalaması 7-7,5 seviyelerine gerilemiş, bu değerler sonrası birtakım çalışmalarda \%40-50 olarak belirtilen uzun dönem mortalite oranları çalışma hastalarımızda \%30 olarak gerçekleşmiştir(32).

Her iki tedavi yönteminin, Covid-19 enfeksiyonu sırasında arttığı çalışmalarla da belirlenmiş olan IL-6 seviyelerine etkileri de araştırıldı(33,34). Laboratuvar testlerinden birçok parametre hastalık şiddeti ile ilişkilendirilmiştir ancak özellikle IL-6 bu alanda en çok üzerinde durulan parametre olmuştur ve IL- 6 'nın da hastalık şiddetini öngördüğü bildirilmiştir(35). IL-6 ‘yı hedefleyerek SSS ve SF gelişimini kontrol altına almak için kullanılan Tosilizumaba benzer şekilde CPFA yöntemi de etkin şekilde IL-6 seviyelerinde düşüş sağlamıştır.

SARS-CoV-2 enfeksiyonunda hem enfeksiyon nedenli hem de IL-6'ya sekonder yükselmiş CRP değerleri izlenebilmektedir(36). CPFA grubunda CRP seviyeleri anlamlı olacak şekilde azalmıştır. Tosilizumab grubunda da CRP değerlerinde kısmi düşüş izlenmiştir.

Her iki grup arasında en belirgin farklılık, CPFA tedavisinin lehine olacak şekilde inotrop kullanımındaki azalmalarda izlenmiştir. Aradaki bu farkın; CPFA uygulamasının SSS ve SF gelişmesine sebep olan inflamatuar sitokinlerin ile beraber diğer toksik partikülleri de non selektif olarak plazmaferez yöntemiyle kandan temizlemesine ve uygulama sırasında veya sonrasında hemodiyafiltrasyon olarak uygulanabilmesine bağlı olduğu düşünülmüştür.

Çalışmamızın bazı kısıtlılıkları bulunmaktadır. Bunlardan en önemlisi çalışmamızın retrospektif olarak düzenlenmiş bir çalışma olmasıdır. Pandemi başladığı dönemlerde yoğun bakım koşullarında ve pandemi ile mücadele esnasında, prospektif randomize bir çalışma tasarlamanın zorlukları gözardı edilemez. Bir diğer kısıtlılık, çalışmanın araştırıldığı dönemde CPFA ve Tosilizumab uygulanan vaka sayılarının azlığıdır. Bu çalışmadaki beklentimiz; CPFA ve Tosilizumab ile ilgili tecrübelerin hızı bir şekilde sunularak, Covid-19 hastalığı sürecinde gelişen SSS ve SF tedavisinde bir alternatif olabileceğinin gösterilmesidir. Bununla ilgili yapılacak daha geniş kapsamlı, prospektif çalışmalar konuya daha da ışık tutacaktır.

\section{Sonuç}

Covid-19 hastalığında, şiddetli progresyon gösteren hastalarda SSS ve SF olarak adlandırılan kontrolsüz sitokin üretimi gözlenmekte ve bu durumun artmış mortalitenin nedenlerinden biri olduğu düşünülmektedir.

Çalışmamızda SSS ve SF geliştiğini düşündüğümüz hastalara uyguladığımız CPFA veya Tosilizumab tedavilerinin, oksijenizasyona, morbidite ve mortalite ile diğer sistemlere etkilerini inceledik. CPFA uygulamasının özellikle oksijenizasyon ve sıvı dengesi hususunda olumlu etkileri daha belirgin olmakla birlikte, iki tedavi yöntemi de hastaların oksijenizasyonunda, klinik ve laboratuvar bulgularında düzelmeler sağlamıştır.

SSS ve SF geliştiği düşünülen Covid-19 hastalarında, özellikle hastalığın erken evresinde kullanılmak kaydıyla, hastalıktaki kötüye gidişin önüne geçilmesinde her iki tedavi yöntemi de umut vadetmektedir.

Etik onam: Çalışmamızın etik kurul onayı Sağlık Bakanlığı ile Sağlık Bilimleri Üniversitesi, Hamidiye Klinik Araştırmalar Etik Kurulu'nun 17/06/2020 tarih ve 18521 sayılı yazısı doğrultusunda alınmıştır.

\section{Yazar Katkıları:}

Konsept: T.E.

Literatür Tarama: B.B.G; C.E.

Tasarım: S.K., C.E.

Veri toplama: T.E., B.B.G.

Analiz ve yorum: T.E., A.E.

Makale yazımı: T.E.

Eleştirel incelenmesi: S.K., A.E.

Çıkar Çatışması: Herhangi bir çıkar çatışmamız bulunmamaktadir.

Finansal Destek: Çalışmamıza finansal kaynak ve/veya katkı sağlayan herhangi bir kurum, kuruluş ve kişiler bulunmamaktadir.

\section{Kaynaklar}

1. Huang $C$, Wang $Y$, Li X, Ren L, Zhao J, Hu Y, et al. Clinical features of patients infected with 2019 novel coronavirus in Wuhan, China. Lancet 2020;395:497-506.

2. https://coronavirus.jhu.edu/map.html (Son erişim: 07.04.2021)

3. Zaim S, Chong JH, Sankaranarayanan $V$ and Harky A. COVID-19 and Multiorgan Response. Curr Probl Cardiol. 2020 Apr 28 : 100618.

4. Mehta P, McAuley DF, Brown M, Sanchez E, Tattersall RS, Manson JJ; HLH across Speciality Collaboration, UK. COVID-19: consider cytokine storm syndromes and immunosuppression. Lancet. 2020;395(10229):1033-4.

5. Bajema KL, Oster AM, McGovern OL, Lindstrom $S$, Stenger MR, Anderson TC, et al. Persons Evaluated for 2019 Novel Coronavirus- United States, January 2020. MMWR Morb Mortal Wkly Rep 2020; 69(6): 166-70.

6. Panagiotou A, Gaiao S, Cruz ND. Extracorporeal therapies in sepsis. Journal of Intensive Care Medicine, 2013, 28.5: 281-95.

7. Cesano G, Livigni S, Vallero A, Olivieri C, Borca M, Quarello $F$, et al. Treatment of septic shock with the use of CPFA (associated plasma filtration and adsorption): impact on hemodynamics monitored with PiCCO. G Ital Nefrol 2002; 20:258-63.

8. Davies R, Choy E. Clinical experience of IL-6 blockade in rheumatic diseases-implications on IL- 6 biology and disease pathogenesis. In: Seminars in immunology. Academic Press, 2014. p. 97-104.

9. Wolf J, Rose-John S, Garbers C. Interleukin-6 and its receptors: a highly regulated and dynamic system. Cytokine, 
2014, 70.1: 11-20.

10. Jones SA, Scheller J, Rose-John S. Therapeutic strategies for the clinical blockade of IL-6/gp130 signaling. The Journal of clinical investigation, 2011, 121.9: 3375-83.

11. Kaly L, Rosner I. Tosilizumab-A novel therapy for non-organ-specific autoimmune diseases. Best practice \& research Clinical rheumatology, 2012, 26.1: 157-65.

12. Yokota $S$, Imagawa $T$, Mori $M$, Miyamae $T$, Aihara $Y$, Takei $S$, et al. Efficacy and safety of Tosilizumab in patients with systemic-onset juvenile idiopathic arthritis: a randomised, double-blind, placebo-controlled, withdrawal phase III trial. The Lancet, 2008, 371.9617: 998-1006.

13. Gabay C, Emery P, Vollenhoven Rv, Dikranian A, Alten R, Pavelka K, et al. Tosilizumab monotherapy versus adalimumab monotherapy for treatment of rheumatoid arthritis (ADACTA): a randomised, double-blind, controlled phase 4 trial. The Lancet, 2013, 381.9877: 1541-50.

14. Grupp SA, Kalos $M$, Barrett D, Aplenc R, Porter DL, Rheingold $S R$, et al. Chimeric antigen receptor-modified $T$ cells for acute lymphoid leukemia. N Engl J Med 2013;368:1509-18.

15. Winkler $U$, Jensen $M$, Manzke $O$, Schulz H, DiehI V, Engert A . Cytokine-release syndrome in patients with B-cell chronic lymphocytic leukemia and high Lymphocyte counts after treatment with an anti-CD20 monoclonal antibody (rituximab, IDEC-C2B8). Blood 1999;94:2217-24 .

16. Xu Z, Shi L, Wang Y, Zhang J, Huang L, Zhang C, et al. Pathological findings of COVID-19 associated with acute respiratory distress syndrome. The Lancet respiratory medicine. 2020;8(4):420-2.

17. Shimizu M. Clinical features of cytokine storm syndrome. In: Cron R, Behrens E. editors. Cytokine Storm Syndrome. Cham: Springer; (2019). 31-42.

18. Rothan HA, Byrareddy SN. The epidemiology and pathogenesis of coronavirus disease (COVID-19) outbreak. Journal of autoimmunity, 2020, 109: 102433.

19. Yao $Q$, Wang $P$, Wang $X$, Qie $G$, Meng $M$, Tong $X$, et al. $A$ retrospective study of risk factors for severe acute respiratory syndrome coronavirus 2 infections in hospitalized adult patients. Pol Arch Intern Med. 2020; 130 (5): 390-9.

20. Peschel G, Jung EM, Fisser C, Putz FJ, Werteheimer T, Sinner $B$, et al. Interstitial lung opacities in patients with severe COVID-19 pneumonia by bedside high-resolution ultrasound in association to $\mathrm{CO} 2$ retention. Clinical Hemorheology and Microcirculation, 2020, Preprint: 1-11.

21. Kang $S$, Tanaka $T$, Narazaki M, Kishimoto $T$. Targeting interleukin-6 signaling in clinic. Immunity, 2019, 50.4: 100723.

22. Pang QL, He WC, Li JX, Huang L. Symptomatic and optimal supportive care of critical COVID-19: A case report and literature review. World journal of clinical cases, 2020, 8.23: 6181.

23. McCreary EK, Jason MP. Coronavirus disease 2019 treatment: a review of early and emerging options. In: Open forum infectious diseases. US: Oxford University Press, 2020. p. ofaa105.

24. Qin C, Zhou L, Hu Z, Zhang S, Yang S, Tao Y, et al. Dysregulation of immune response in patients with coronavirus 2019 (COVID-19) in Wuhan, China. Clinical infectious diseases, 2020, 71.15: 762-8.

25. Guan WJ, Ni ZY, Hu Y, Liang WH, Ou CQ, He JX, et al. Clinical characteristics of coronavirus disease 2019 in
China. New England journal of medicine, 2020, 382.18: 1708-1720.journal of medicine 382.18 (2020): 1708-20.

26. Shi H, Han X, Jiang N, Cao Y, Alwalid O, Gu J, et al. Radiological findings from 81 patients with COVID-19 pneumonia in Wuhan, China: a descriptive study. The Lancet infectious diseases 20.4 (2020): 425-34.

27. Zhou P, Yang XL, Wang XG, Hu B, Zhang L, Rui H, et al. Discovery of a novel coronavirus associated with the recent pneumonia outbreak in humans and its potential bat origin. BioRxiv (2020).

28. Alhazzani W, Møller MH, Arabi YM, Loeb M, Gong MN, Fan $E$, et al. Surviving Sepsis Campaign: guidelines on the management of critically ill adults with Coronavirus Disease 2019 (COVID-19). Intensive Care Med. 2020; 1- 34.

29. Villar J, Blanco J, Campo Rd, Ojeda DA, Dominguez FJD, Muriel A, et al. Assessment of $\mathrm{PaO} 2 / \mathrm{FiO} 2$ for stratification of patients with moderate and severe acute respiratory distress syndrome. BMJ open, 2015, 5.3.

30. Villar J, Perez-Mendez L, Blanco J, Anon JM, Blanch L, Belda J, et al. A universal definition of ARDS: the PaO 2/FiO 2 ratio under a standard ventilatory setting-a prospective, multicenter validation study. Intensive care medicine, 2013, 39.4: 583-92.

31. Khwannimit $B$, Bhurayanontachai $R$, Vattanavit $V$. Comparison of the accuracy of three early warning scores with SOFA score for predicting mortality in adult sepsis and septic shock patients admitted to intensive care unit. Heart \& Lung, 2019, 48.3: 240-244.

32. Ferreira FL, Bota DP, Bross A, Melot $C$, Vincent JL. Serial evaluation of the SOFA score to predict outcome in critically ill patients. JAMA. 2001;286(14):1754-8.

33. Zhang $\mathrm{C}, \mathrm{Wu} \mathrm{Z}$, Li JW, Zhao H, Wang GQ. The cytokine release syndrome (CRS) of severe COVID-19 and Interleukin6 receptor (IL- 6R) antagonist Tocilizumab may be the key to reduce the mortality. Int J Antimicrob Agents. (2020) 29:105954.

34. Coomes EA, Haghbayan H. Interleukin-6 in COVID-19: a systematic review and meta-analysis. Reviews in medical virology, 2020, 30.6: 1-9.

35. Han $H, M a ~ Q$, Li C, Liu R, Zhao L, Wang W, et al. Profiling serum cytokines in COVID-19 patients reveals IL-6 and IL10 are disease severity predictors. Emerg Microbes Infect 2020;9:1123-30.

36. Ruan $Q$, Yang $K$, Wang $W$, Jiang $L$, Song J. Clinical predictors of mortality due to COVID-19 based on an analysis of data of 150 patients from Wuhan, China. Intensive care medicine, 2020, 46.5: 846-8. 